\title{
Preparation and Characterization of Commercial Polyethyleneterephthalate Membrane for Fuel Cell Applications
}

\author{
Abdel-Hady EE*, Abdel-Hamed MO and Gomaa MM \\ Physics Department, Faculty of Science, Minia University, Minia, Egypt
}

\begin{abstract}
Commercial Polyethyleneterephthalate (PET) based proton exchange membrane was prepared by UV-radiation grafting of styrene onto PET films. The effect of irradiation time and different concentrations of the monomer on the degree of grafting (D.G.) has been studied. It was found that the DG increases linearly with increasing the irradiation time and monomer concentration, reaching a maximum at a certain level. The effect of chlorosulfonic acid concentrations on ion exchange capacity (IEC) and tensile strength also studied to find the optimum concentration of chlorosulfonic acid for using in the sulfonation process. The range of IEC, 0.2 to $0.775 \mathrm{~m} \mathrm{~mol} / \mathrm{g}$, resulting from treating styrene grafted and sulfonated PET (PET-g-PSSA) membranes with different chlorosulfonic acid levels showed that chlorosulfonic acid is an effective tool to control IEC. Fourier transform infrared (FTIR) spectroscopic analysis confirmed grafting and sulfonation onto PET Films. In addition, thermogravimetric analysis was used to investigate the behavior of the original PET film and PET-g-PSSA membranes. The methanol permeability and the proton conductivity of PET-g-PSSA film with D.G. $166 \%$ were found to be $1.2 \times 10^{-8}$ and $58 \mathrm{~m}$ S/cm, respectively, better than those of Nafion 212 membrane measured with the same instruments under the same conditions. Since they have lower cost, higher conductivity and lower methanol permeability, PET-g-PSSA could be better used instead of Nafion in direct methanol fuel cells.
\end{abstract}

Keywords: PET membrane; UV-radiation grafting; Sulfonation; Proton conductivity

\section{Introduction}

Worldwide growing demand for fossil fuels, which are currently the most convenient energy source, is expected to lead to an energy crisis, unless sustainable and alternate fuels become available. Furthermore, their combustion emissions are polluting the environment to the threshold of creating health problems, and the carbon dioxide emissions are implicated in global warming [1]. Direct methanol fuel cell (DMFC) is considered as a highly promising power source. It is based on proton exchange membrane (PEM) fuel cell technology. It possess a number of advantages, such as a liquid fuel, quick refueling, low cost of methanol and the compact cell design, making it suitable for various potential applications, including stationary and portable applications, and it is favored for use as commercial products in automobiles, residential homes, and in portable devices, such as laptops and cell phones. DMFCs are also environmentally friendly. Although carbon dioxide is produced, there is no production of sulfur or nitrogen oxides.

The proton exchange membrane (PEM) is a key device in fuel cells, which acts as proton transferring electrolyte, as well as provides a barrier to the passage of electrons between the electrodes [2]. At the present time, per fluorinated membranes, Nafion are the most commonly used PEM around the world, due to their superior chemical and electrochemical stability, as well as high proton conductivity under fuel cell operating conditions [3]. However, some disadvantages, such as their high preparation cost, decrease in ion conductivity at high temperatures, and their high methanol permeability, severely limit their commercialization in fuel cells. Therefore, much effort has been expended in developing new membranes to circumvent these disadvantages [4-6]. Radiation graft polymerization is one of the promising methods, which enables introduction of active monomer functional group at inner polymer chains in film for the modification of the chemical and physical properties of a wide range of polymer materials. Various kinds of grafting polymerization techniquesincluding ion-radiation induced, photo-induced (UV and chemical initiator) and plasma-induced grafting polymerizations-have been developed in the last few decades [7-9]. However, the UV-radiation technique is more available and less expensive than other techniques [10]. In comparison with $\gamma$-ray radiation grafting, UV-induced photografting is very simple and safe, and is less damaging to the membranes because significant degradation of the membrane main chains can be avoided [11].

Several studies identify that poly(ethylene-alt-tetrafluoroethylene) (PTFE) [12-14], poly(vinylidene fluoride) (PVDF) [15-17], poly(tetrafluoroethylene-co-perfluoropropyl vinyl ether) (PFA) [18] and cross linked polytetrafluoroethylene (ETFE) $[18,19]$ are promising base polymers. Styrene is the most frequently used monomer due to its high thermal stability and moderate sulfonation process of the aromatic ring [4]. The Polyethyleneterephthalate (PET) based proton exchange membrane for using in fuel cells was successfully prepared by gamma radiation-induced graft copolymerization of styrene monomer onto PET film, and the consequent selective sulfonation of the grafting chain in the film state using chlorosulfonic acid $\left(\mathrm{CISO}_{3} \mathrm{H}\right)$ by Mostak et al. [20].

The present research focuses on developing a non-fluorinated, inexpensive proton exchange membrane. The PET-based PEM was prepared successfully by UV-radiation grafting of styrene onto PET films. Figure 1 shows the chemical structure of the PET monomer,

*Corresponding author: Abdel-Hady EE, Physics Department, Faculty of Science, Minia University, Minia, Egypt, Tel/ Fax: +2086 2363011; E-mail: esamhady@yahoo.com

Received May 20, 2013; Accepted August 24, 2013; Published August 26, 2013

Citation: Abdel-Hady EE, Abdel-Hamed MO, Gomaa MM (2013) Preparation and Characterization of Commercial Polyethyleneterephthalate Membrane for Fuel Cell Applications. J Membra Sci Technol 3: 122. doi:10.4172/2155-9589.1000122

Copyright: ( 2013 Abdel-Hady EE, et al. This is an open-access article distributed under the terms of the Creative Commons Attribution License, which permits unrestricted use, distribution, and reproduction in any medium, provided the original author and source are credited. 


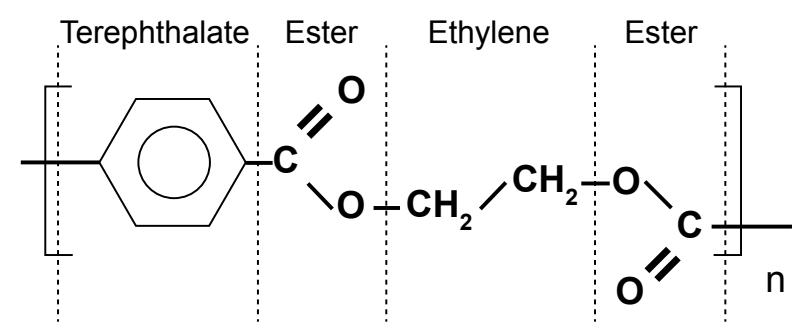

Figure 1: The chemical structure of the PET monomer.

grafted film was then sulfonated by chlorosulfonic acid to form proton exchange membrane. The effects of grafting and sulfonation conditions such as monomer and chlorosulfonic acid concentration, irradiation time were investigated. The characterizations of the membranes, including different chemical and physical parameters such as water uptake, tensile strength, ion exchange capacity, proton conductivity, thermal durability and FTIR spectroscopy were also studied.

\section{Experimental Methods}

\section{Materials}

Commercial Polyethylene terephthalate (PET) film of $51 \mu \mathrm{m}$ thickness purchased from Cs Hyde Company, USA, was used as a polymer matrix. Styrene of purity more than $99 \%$ (Sigma-Aldrich) was used as the grafting monomer without any further purification, and the photo initiator (benzophenone) was purchased from Oxford laboratory, India. Chloroform was used to remove homopolymer after grafting. 1, 2 Dichloromethane (Lobachemie, India), chlorosulfonic acid (Fluka) and methanol (Fluka) were used as received. Sodium chloride $(\mathrm{NaCl})$ and sodium hydroxide $(\mathrm{NaOH})$ were used for titrimetric analysis and purchased from Adwic. Egypt, Nafion NR 212 (DuPont) was used as a reference material.

\section{Grafting procedure}

The PET films of thickness $51 \mu \mathrm{m}$ were cut into square pieces of known weight, washed with acetone, and then dried in a vacuum oven at $60^{\circ} \mathrm{C}$ for $1 \mathrm{~h}$. The dried films were placed into a glass ampoule containing monomer solution of known concentration. Photo grafting mixture consists of methanol, which is used as a solvent, benzophenone (BP, photo initiator, with concentration $2 \%$ ), Styrene (monomer) with different concentrations $(25,30,35$ and $40 \%)$ at $50^{\circ} \mathrm{C}$. The different parameters affecting the degree of grafting of styrene onto PET were assessed. These parameters include the grafting time and monomer concentration. By changing the grafting time (1-8 hours), PET films with different degree of grafting were obtained. After grafting, polystyrene/ PET films were washed several times with a large amount of chloroform to remove any excess unreacted monomer or styrene homopolymer. The process was repeated with fresh chloroform to ensure the complete removal of any residual monomer and homopolymer occluded within the polymer. The grafted films were then dried in a vacuum oven at $80^{\circ} \mathrm{C}$, until a constant weight was obtained. The degree of grafting (D.G.\%) was calculated using the equation (1)

$$
\text { D.G }(\%)=\frac{\mathrm{W}_{\mathrm{g}-\mathrm{W} 0}}{\mathrm{~W}_{0}} \times 100
$$

Where $\mathrm{W}_{\mathrm{g}}$ and $\mathrm{W}_{\mathrm{o}}$ are the weights of grafted and original PET films, respectively.

\section{Sulfonation}

Sulfonation of the PET grafted films was carried out by immersing PET films with different degree of grafting in different concentrations $(0.2,0.5,0.7$ and 1$)(\mathrm{v} / \mathrm{v}) \%$ of chlorosulfonic $\left(\mathrm{ClSO}_{3} \mathrm{H}\right)$ acid in $1-2$ dichloromethane. The sulfonation was performed at room temperature for 1 hour. After sulfonation, the membranes were removed from sulfonating solution and immersed in fresh dichloromethane for 3 hours, followed by washing in 1-2 dichloromethane to remove any residual acid, so as to reduce any effect of swelling that may occur if water was used for the initial washing stage, and finally hydrolysis in deionized water at $80^{\circ} \mathrm{C}$ for 24 hours before measurements. Figure 2 shows the preparation process of the proton-conducting membranes.

\section{Fourier transforms infrared spectra (FTIR)}

The functional groups of the grafted membrane were measured using BRUKER ALFA FTIR USA spectrometer with resolution $0.9 \mathrm{~cm}^{-1}$.

\section{Thermal Gravinetric Analysis (TGA)}

Thermo-gravimetric analyzer (TGA) instrument model Q50, USA was used to characterize the thermal stability of the membranes with heating rate $10^{\circ} \mathrm{C} \mathrm{min}^{-1}$ under nitrogen atmosphere.

\section{Tensile strength}

The tensile tests were measured at room temperature by UNIVERSAL MATERIALS TESTING MACHINE LLOYD (model LR $5 \mathrm{~K}$ plus). The measurements were performed at a cross-head speed set at a constant speed of $10 \mathrm{~mm} / \mathrm{min}$.

\section{Measurement of ion exchange capacity}

Ion Exchange Capacity (IEC) of the sulfonated samples was measured using a typical titration method. The dried membrane in the protonic form was equilibrated with $25 \mathrm{ml}$ of $3 \mathrm{M} \mathrm{NaCl}$ solution for 24 hours. A large excess of $\mathrm{Na}^{+}$ions in the solution ensured nearly complete ion exchange. Then, $10 \mathrm{ml}$ of the solution was titrated against $0.05 \mathrm{M} \mathrm{NaOH}$ solution using phenolphthalein as indicator. Finally, drops of $0.05 \mathrm{M} \mathrm{NaOH}$ solution were added, until the color of solution change from colorless to pink. The IEC was calculated using the following equation:

$$
\mathrm{IEC}=\frac{0.05 \times \mathrm{n} \times \mathrm{V}_{\mathrm{NaOH}}}{\mathrm{W}_{\mathrm{dry}}}
$$

Where $\mathrm{V}_{\mathrm{NaOH}}(\mathrm{ml})$ is the volume of the $0.05 \mathrm{M} \mathrm{NaOH}$ solution used for titration, $\mathrm{n}$ is the factor corresponding to the ratio of the amount of $\mathrm{NaCl}$ taken to immerse the polymer to the amount used for titration that is 2.5 , and $\mathrm{W}_{\mathrm{dry}}$ is the dry weight of the polymer electrolyte

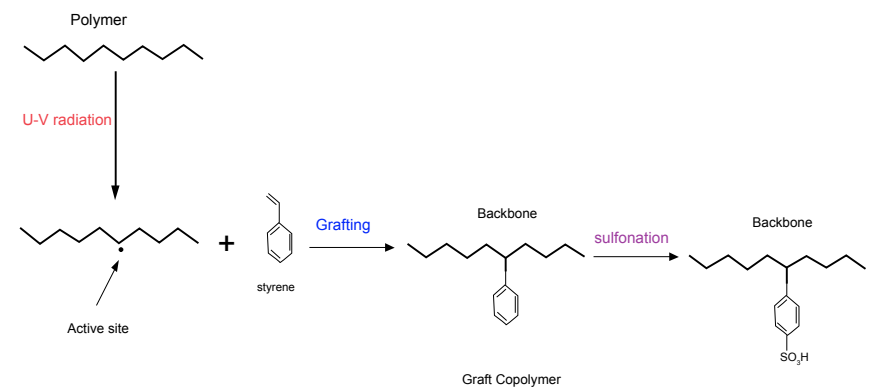

Figure 2: The preparation process of the proton-conducting membranes. 
Citation: Abdel-Hady EE, Abdel-Hamed MO, Gomaa MM (2013) Preparation and Characterization of Commercial Polyethyleneterephthalate Membrane for Fuel Cell Applications. J Membra Sci Technol 3: 122. doi:10.4172/2155-9589.1000122

membrane in the protonic form.

\section{Water uptake}

The water uptake was determined in the following way: at first, the membrane samples with different degree of grafting after sulfonation were dried under vacuum for 1 hour at $80^{\circ} \mathrm{C}$, and then weighted. They were then soaked in deionized water for 2 days, until swelling equilibrium was achieved. The soaked membranes were carefully blotted with a filter paper to remove water on the surface, followed by weight measurement.

$$
\text { Water uptake }(\%)=\frac{\mathrm{W}_{\text {swollen }}-\mathrm{W}_{\text {dry }}}{\mathrm{W}_{\text {dry }}} \times 100
$$

Where $\mathrm{W}_{\text {swollen }}$ is the weight of the swollen membrane and $\mathrm{W}_{\mathrm{dry}}$ is the weight of the dried membranes.

\section{Proton conductivity}

Proton conductivity measurements of the sulfonated grafted membranes were derived from AC impedance spectroscopy measurements over a frequency range of 50 to $5 \mathrm{M} \mathrm{Hz}$ with an oscillating voltage of 50-500 mV, using a system based on a HIOKI LCR Hi-Tester, Model:3532, Japan. Each membrane sample was cut into sections 2.5 $\mathrm{cm} \times 2.5 \mathrm{~cm}$ prior to being mounted in the cell. The cell was placed in a temperature controlled container open to air by a pinhole, where the sample was equilibrated at $100 \% \mathrm{RH}$ at ambient atmospheric pressure and clamped between two electrodes. The proton conductivities of the samples were measured in the longitudinal direction, and were calculated from the impedance data using the following relationship:

$$
\sigma=\frac{\mathrm{L}}{\mathrm{RS}}
$$

where $\sigma$ is the proton conductivity (in Simon/cm), L is the distance between the electrodes used to measure the potential $(\mathrm{L}=1 \mathrm{~cm}), S$ is the membrane cross-sectional surface area (membrane width $\times$ membrane thickness) required for protons to penetrate through the membrane (in $\mathrm{cm}^{2}$ ), and $\mathrm{R}$ is derived from the low intersection of the high frequency semicircle on a complex impedance plane with the $\operatorname{Re}(\mathrm{Z})$ axis.

\section{Methanol permeability}

Methanol permeability measurement was carried out at room temperature using a liquid diffusion cell composed of two compartments containing solution $A$ and $B$. One compartment $A\left(V_{A}=50 \mathrm{ml}\right)$ was filled with $5 \mathrm{~mol} / \mathrm{L}$ methanol solution, the other compartment $\left(V_{B}=50\right.$ $\mathrm{ml}$ ) was filled with deionized water only. The tested membrane was immersed in deionized water for hydration before measurements, and then vertically placed between the two compartments by a screw clamp. Both compartments were kept under stirring slightly during the permeation experiments. Amount of methanol diffused from compartment $\mathrm{A}$ to $\mathrm{B}$ across the membrane was measured over time. The methanol permeability $\mathrm{P}$ was calculated by the following equation:

$$
\mathrm{P}=\frac{\mathrm{KV}_{\mathrm{B}} \mathrm{L}}{\mathrm{AC}_{\mathrm{A}}}
$$

Where $\mathrm{k}$ is the slope of the straight line plot of methanol concentration in solution $B$ versus permeation time, $V_{B}, L$ and $A$ are the volume of solution $\mathrm{B}$, the thickness and the effective area of the tested membrane, respectively.

\section{Single cell test}

Single cell test was conducted using $2 \mathrm{M}$ methanol aqueous solution in the passive mode (the methanol at the anode and at the cathode,
$\mathrm{O}_{2}$ supported from the surrounding air without air flow) at room temperature and atmospheric conditions. The cell was connected to a voltammeter and the cell voltage was recorded as a function of time.

\section{Results and Discussion}

\section{Effect of monomer concentration}

Polyethylene terephthalate (PET) films were placed into a glass ampoule containing monomer solution with different concentrations and irradiated with U-V radiation. The degree of grafting D.G (\%) of styrene monomer onto the commercial PET membrane as a function of monomer concentration has been shown in Figure 3. The degree of grafting (D.G.) increased from 89\% (at 20 volume \% styrene concentration) to $166 \%$ (at 30 volume \% styrene concentration), because of increasing copolymerization between styrene and PET film. The Degree of grafting then decreased from $166 \%$ (at 30 volume \% styrene concentration) to $54 \%$ (at 40 volume $\%$ styrene concentration), because of dominating homopolymer formation that hindered the movement of styrene towered PET films. It was reported that the homopolymerization effect increased the viscosity of the grafting solution, hindering the movement of monomer toward the substance, and consequently, reduced the grafting yield [21,22]. So, the better concentration for preparation grafting of styrene onto PET films by UV radiation technique was found to be 30 volume \% styrene concentrations.

\section{Effect of irradiation time}

Grafting onto PET film was carried out as a function of irradiation time, keeping the monomer concentration constant at $30 \%$ volume styrene concentration. PET films were placed with a styrene solution into glass ampoules. The ampoules were irradiated with grafting solution ( $30 \%$ styrene concentration). Figure 4 shows the UVphoto grafting of styrene into PET films with $30 \%$ monomer styrene concentration as a function of irradiation time. As can be seen from the figure, the degree of grafting increases gradually with the increase of radiation time up to 4 hours, then a suddenly increase can be seen

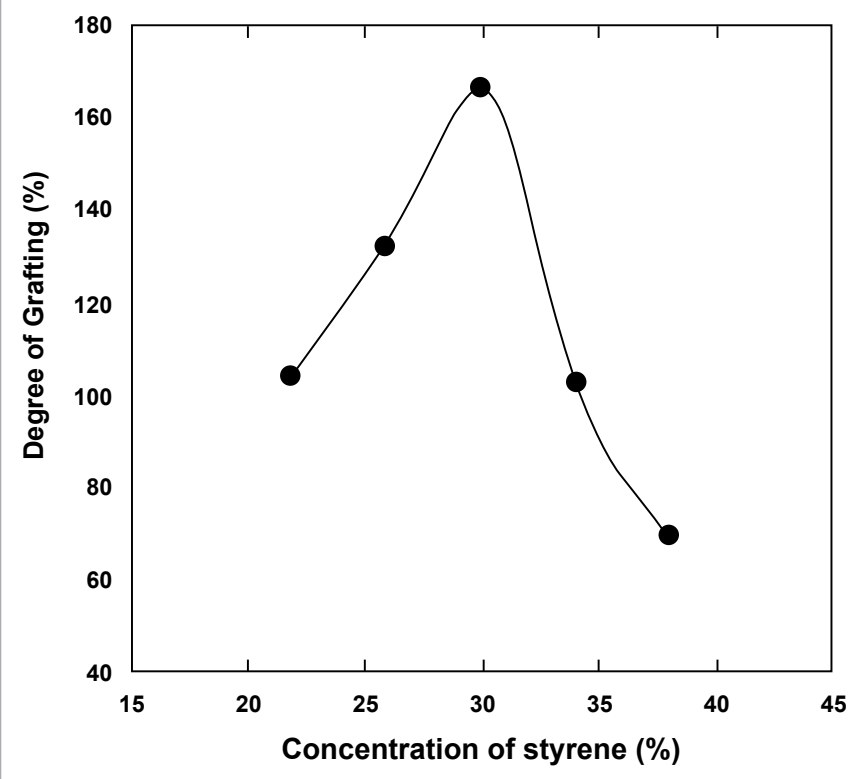

Figure 3: Degree of grafting (D.G) of styrene onto PET film as a function of concentration of styrene (\%). 
Citation: Abdel-Hady EE, Abdel-Hamed MO, Gomaa MM (2013) Preparation and Characterization of Commercial Polyethyleneterephthalate Membrane for Fuel Cell Applications. J Membra Sci Technol 3: 122. doi:10.4172/2155-9589.1000122

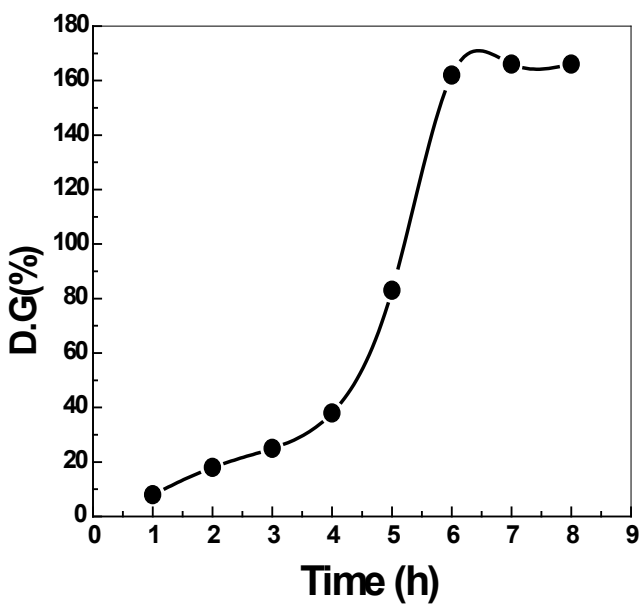

Figure 4: Degree of grafting (D.G. \%) of styrene onto the PET film as a function of UV- Irradiation time.

up to 6 hours. After 6 hours radiation time, no appreciable increase in the degree of grafting was observed. This behavior was observed in the simultaneous radiation grafting of styrene into PTFE films, where the grafting increases almost linearly with the increase in the radiation dose, and reasonably high graft levels up to $70 \%$ were achieved $[23,24]$. However, higher irradiation doses are not preferred due to the deterioration of mechanical properties [25]. By increasing radiation time, the number of free radicals formed in the grafting solution also increases; leads to more monomers diffuse to the film resulting in an increase in the degree of grafting. After 6 hours, a saturation of the radical sites can be noticed, i.e. the equilibrium degree of grafting value $(166 \%)$ was reached at 6 hours.

\section{Sulfonation and ion exchange capacity}

The PET film which has the highest degree of grafting value (166\%) was sulfonated with different concentration of chlorosulfonic acid $(0.2,0.5,0.7,1)(\mathrm{v} / \mathrm{v}) \%$ in $1-2$ dichloromethane. It was observed that low chlorosulfonic acid $\left(\mathrm{CISO}_{3} \mathrm{H}\right)$ solution concentration give low IEC and increased with increasing concentration of chlorosulfonic acid, (Figure 5), due to the incorporation of the increased number of $\mathrm{SO}_{3} \mathrm{H}$ groups into the grafted PET film. At 166\% degree of grafting and $1 \%$ chlorosulfonic acid concentration, the IEC of the PET-g-PSSA membrane reached a maximum of $0.775 \mathrm{~m} \mathrm{~mol} / \mathrm{g}$, which is comparable to the Nafion 212 membrane (IEC of $0.841 \mathrm{~m} \mathrm{~mol} / \mathrm{g}$ ), measured with the same instrument under the same conditions. The IEC for PET-gPSSA (D.G. 166\%) shows higher value than the maximum IEC of the PET grafted membrane prepared under UV radiation by Mostak et al. [20]. They found that the IEC has a value of $0.04385 \mathrm{mmol} \mathrm{g}^{-1}$ at $12.7 \%$ degree of grafting (D.G.). The number of sulfonic acid groups in the membrane increases with the increase in the D.G. At higher styrene concentrations, more benzene rings are in contact with sulfonic acid groups, which results in more sulfonic acid groups in the membrane. However, the efficiency of the sulfonation reaction depends to large extent on whether or not the membrane is grafted through its thickness [26]. If the samples contained a core of ungrafted parts, sulfonation was incomplete at room temperature due to insufficient swelling of the samples and the difficulty of diffusion of the sulfonating agent.

\section{Tensile strength}

In the present work, to find the optimum concentration of chlorosulfonic acid $\mathrm{ClSO}_{3} \mathrm{H}$ for sulfonation of grafted PET films, the tensile strengths of the sulfonated film which has the highest degree of grafting value (166\%) with different concentration of chlorosulfonic acid $(0.2,0.5,0.7,1)(\mathrm{v} / \mathrm{v}) \%$ in 1-2 dichloromethane were measured. Table 1 illustrates the mechanical parameters for Nafion and PETg-PSSA, with degree of grafting $166 \%$ membranes at different concentrations of chlorosulfonic acid. As can be seen from this table, the sulfonation reaction at higher chlorosulfonic acid $\mathrm{ClSO}_{3} \mathrm{H}$ concentration is accompanied with decreasing tensile strength of the film. This can be explained by the fact that the continuous increases in the content of sulfonic acid in the grafted PET film results in the deterioration of mechanical properties of the membranes, because of highly hydrophilic property of the film [27], which make the films, have low tensile strength [28]. After sulfonation with concentration more than $1 \%$ of chlorosulfonic acid, it was observed that the membranes are more fragile. The high IEC and acceptable value of tensile strength at $1 \%$ concentration of chlorosulfonic acid make this concentration of chlorosulfonic acid is the optimum concentration for sulfonation of grafted PET films.

\section{Membranes characterization}

Fourier transforms infrared spectra (FTIR): Figure 6 shows the FTIR spectra of pure, grafted and sulfonated films with D.G (166\%), The original PET film is characterized by a strong band at $730 \mathrm{~cm}^{-1}$, representing the stretching vibration of the $\mathrm{C}=\mathrm{O}-\mathrm{O}$ - (ester group) and the absorption bands at 2870 and $2950 \mathrm{~cm}^{-1}$, representing the symmetric and the asymmetric stretching vibration of $\mathrm{CH}_{2}$ group of ethylene, respectively, as depicted from spectrum $A$. The presence of the benzene ring in the PET films is established by the $=\mathrm{C}-\mathrm{H}$ stretching vibration at $3050 \mathrm{~cm}^{-1}$ and the skeletal $\mathrm{C}=\mathrm{C}$ in-plane stretching vibrations at 1500 and $1600 \mathrm{~cm}^{-1}$, respectively. The Para-substitution of benzene ring is represented by the band at $860 \mathrm{~cm}^{-1}$. The grafting of styrene is confirmed by the mono substitution of the benzene ring of the polystyrene, which is represented by the aromatic out-of-plane $\mathrm{C}-\mathrm{H}$ deformation band at $730 \mathrm{~cm}^{-1}$. The absorption bands at $2975 \mathrm{~cm}^{-1}$ is assigned for the symmetric stretching of $\mathrm{CH}$ of the polystyrene and peak intensity is increased at $1450-1600 \mathrm{~cm}^{-1}$, which proves the monomer was grafted. Sulfonation at the grafted PET film was confirmed by showing two peaks at $1146 \mathrm{~cm}^{-1}$ (asymmetrical stretch) and $1056 \mathrm{~cm}^{-1}$ (symmetrical stretch) for sulfonic acid group. The broad peak at $3410 \mathrm{~cm}^{-1}$ assigned

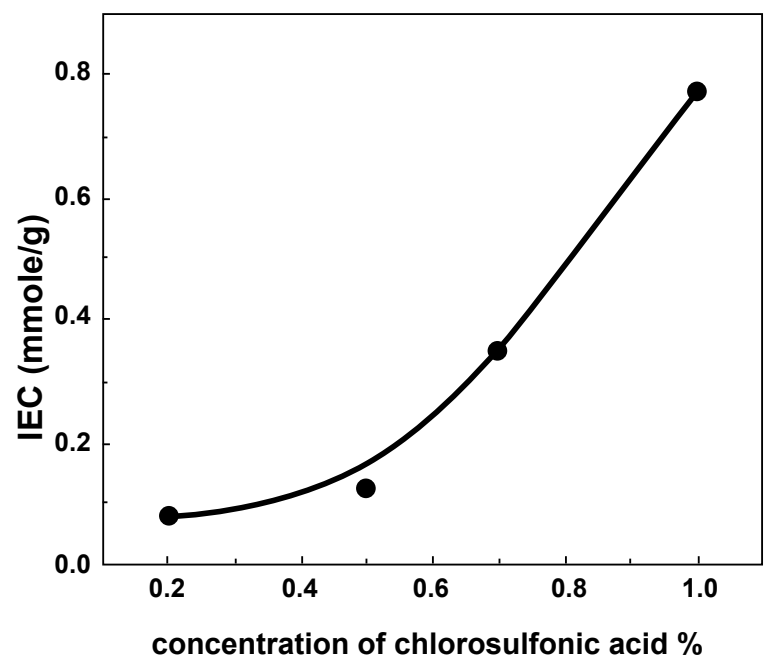

Figure 5: Ion exchange capacity (IEC) as a function of chlorosulfunic acid concentration \%. 


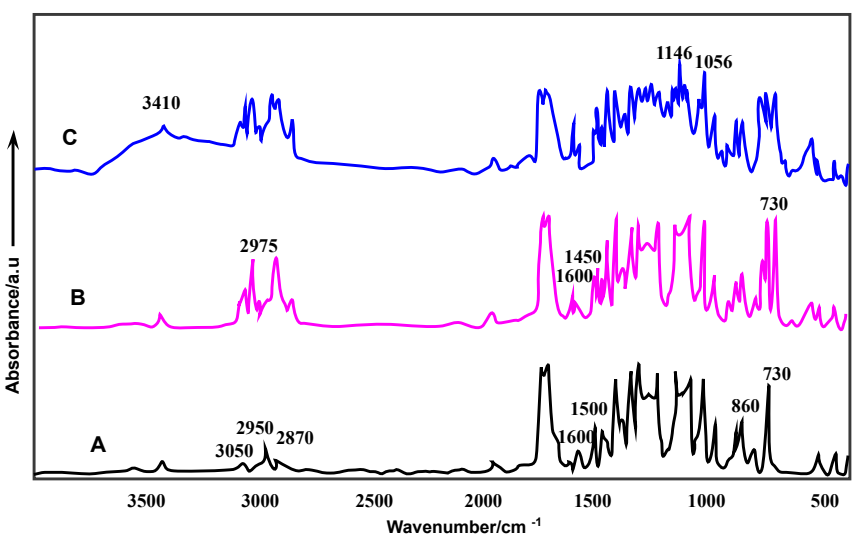

Figure 6: Typical FTIR spectra of (A) original, (B) grafted PET and (C) sulfonated films having a degree of grafting of $166 \%$.

to water molecules involved in hydrogen bonding with the $\mathrm{SO}_{3}$ groups [29]. In addition, the grafted films were found to be not transparent compared to the original PET film, which was transparent. Moreover, their dimensions were found to be increased compared to that of the original films. All this features together confirm the successful grafting of styrene onto PET films.

Thermal Gravimetric Analysis (TGA): The thermal properties of pure PET, PET-g-PSSA and Nafion membranes were preliminarily evaluated by TGA in $\mathrm{N}_{2}$ heating at $10^{\circ} \mathrm{C} \mathrm{min}^{-1}$ as shown in Figure 7. For Pure PET, the main weight loss appears at around $450^{\circ} \mathrm{C}$, which can be attributed to the degradation of the backbone of the polymers. This temperature decreased in the PET-g-PSSA membranes from 450 to $430^{\circ} \mathrm{C}$ indicates that the incorporation of styrene makes the PET film vulnerable to thermal degradation due to incorporation of some weak links into the macromolecular chain. There was a gradual weight loss of PET-g-PSSA membrane. The weight loss at $30-300^{\circ} \mathrm{C}$ is attributed to residual boundary water loss [30], associated with sulfonic acid groups. Decomposition of sulfonic acid groups begins around $300^{\circ} \mathrm{C}$ and completed up to $400^{\circ} \mathrm{C}$; decomposition of the grafted chain occurs above $410^{\circ} \mathrm{C}$ and followed by PET main chain degradation. Nafion 212 exhibits a similar degradation behavior to that of PET-g-PSSA. The major weight loss around $460^{\circ} \mathrm{C}$ is due to the degradation of the backbone of Nafion. The data indicate that the PET-g-PSSA membrane is thermally stable within the temperature range for Proton Exchange Membrane Fuel Cell (PEMFC) applications.

\section{Water uptake}

The water uptake is an important parameter for fuel-cell membranes, and has a direct connection to the proton conductivity and the dimensional stability. Higher water uptake generates more solvated species, which is needed for high conductivity, but unfortunately, greater water content produces mechanically less stable membrane [31]. Figure 8 shows the water uptake as a function of the degree of grafting of the PET based proton conducting membranes. The higher degree of grafting was associated with a higher water uptake (59\%), indicating the presence of hydrophilic sites (sulfonated graft chains) within the hydrophobic PET base films. The same behavior was observed by Abdel-Hady et al. [32]. Using the same instrument and under the same conditions, the water uptake of the Nafion membrane was also measured to be $53 \%$, which is in a good agreement with the obtained value of PET-g-PSSA membrane with degree of grafting
$166 \%$

\section{Proton conductivities}

The proton conductivity of the PET-g-PSSA membranes was estimated using impedance diagrams, acquired in the frequency range $50-10^{6} \mathrm{~Hz}$. All the samples were in the fully water swollen state. Figure 9 shows the impedance spectra of PET-g-PSSA, with D.G. $166 \%$ as an example. It was observed that the resistance decreased with increasing D.G. due to higher content of styrene grafted to the main chain provides more sites for the attack of sulfonic acid group, which is responsible for conduction. Resistance of the membrane obtained from the impedance spectra, and then converted into proton conductivity of the membrane as conduction is the reverse of resistance. Table 2 shows the change of proton conductivity with the degree of grafting at room temperature. The proton conductivity of PET-g-PSSA membrane increases with increasing the degree of grafting due to the increasing in sulfonic acid group. Low degrees of grafting, the polystyrene grafts

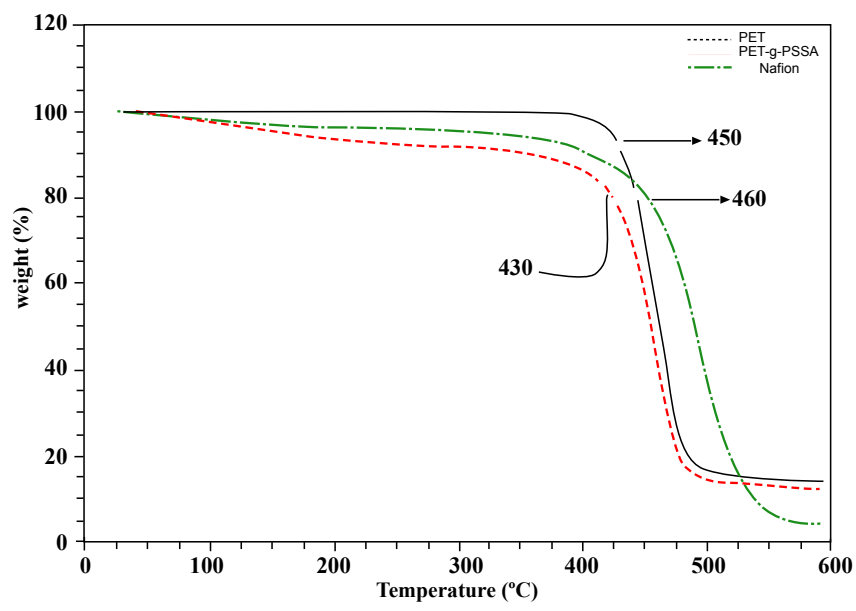

Figure 7: Typical TGA weight loss curves of pure PET, PET-g-PSSA and Nafion membranes.

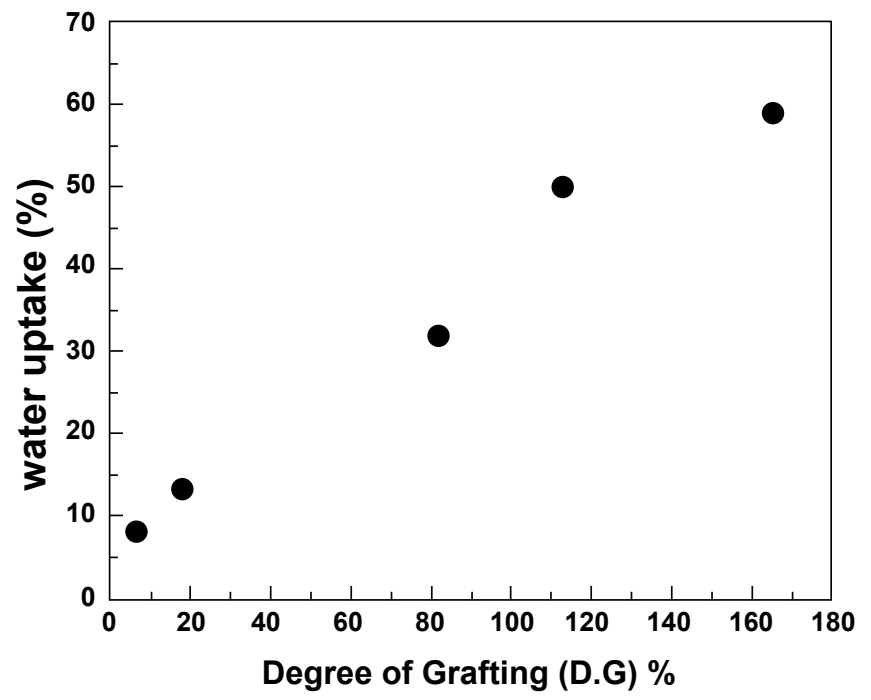

Figure 8: Water uptake as a function of Degree of grafting. 
Citation: Abdel-Hady EE, Abdel-Hamed MO, Gomaa MM (2013) Preparation and Characterization of Commercial Polyethyleneterephthalate Membrane for Fuel Cell Applications. J Membra Sci Technol 3: 122. doi:10.4172/2155-9589.1000122

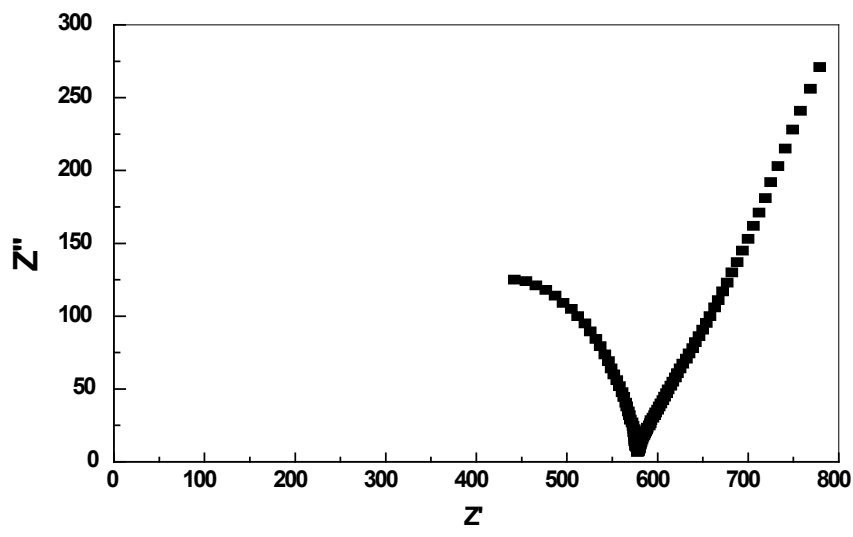

Figure 9: A C impedance spectra for PET-g-PSSA membrane (D.G. = 166\%) at room temperature.

are located near the surface of the film, while its middle remains ungrafted, and subsequently, it exerts high local resistance to proton due to inhomogeneous distribution of ion exchange sites over the area of the membrane. Hydration of the membrane (i.e. incorporation of water molecules into the polymer structure) leads to convert of the acid groups into mobile $\mathrm{H}^{+}$.

The resulting nanophase-separated structure is an interpenetrating network of hydrophobic polymer backbone material providing structural integrity and aqueous domains, allowing proton transport within water-containing channels. The proton conductivity of the material depends on the density of acidic groups. So, it was observed that the films which have high water uptake give high conductivity (Table 2). The maximum value of conductivity for PET-g-PSSA film with D.G. (166\%) was observed to be $58 \mathrm{~m} \mathrm{~S} / \mathrm{cm}$. The conductivity of Nafion 212 membrane was also measured to be $52 \mathrm{~m} \mathrm{~S} / \mathrm{cm}$ with the same instrument under the same conditions for comparison. The prepared membranes show higher conductivity similar to the Nafion membrane, but they are a lot cheaper compared to Nafion or other equivalent membranes. Also, the observed proton conductivity of the PET-g-PSSA membrane is much better (4 times higher), as compared to that of the PET grafted membrane prepared under UV radiation by Mostak et al. [20].

\section{Effect of temperature on the Proton conductivity}

The effect of temperature on conductivity of PET-g-PSSA film with degree of grafting (D.G $=166 \%$ ) is calculated by using impedance diagrams at different temperature ranging from room temperature up to $90^{\circ} \mathrm{C}$. Figure 10 shows the impedance spectra of PET-g-PSSAwith D.G (166\%) different temperatures which converted into proton conductivity. From the impedance diagrams, it was found that the resistance to conducting ions decreases linearly with increasing the temperature up to $90^{\circ} \mathrm{C}$. The elevation of temperature favors both the dynamics of proton transport and the structural reorganization of polymeric chains that is attributed to the activation energy of the conducting ions, which increases with temperature resulting in the increased proton conductivity at higher temperatures.

The proton conductivity $\sigma$ for PET-g-PSSA (D.G=166\%) and Nafion membranes at different temperatures are presented in Figure 11. It was observed that the proton conductivity for both membranes increased linearly as the temperature increases up to $90^{\circ} \mathrm{C}$. Also, it was noticed that the PET-g-PSSA with D.G $=166 \%$ has a proton conductivity ranging from 58 to $97 \mathrm{~m} \mathrm{Scm}^{-1}$, which is attractive for fuel cell application. Moreover, the proton conductivity of the Nafion membrane was found to be ranged from 52 up to $147 \mathrm{~m} \mathrm{Scm}^{-1}$. The increasing of conductivity with increasing temperature is due to

\begin{tabular}{|c|c|c|c|}
\hline Materials & $\begin{array}{l}\text { Concentration of } \\
\text { chlorosulfonic acid \% }\end{array}$ & $\begin{array}{l}\text { Young's } \\
\text { modulus(MPa) }\end{array}$ & $\begin{array}{l}\text { Tensile strength } \\
\text { (MPa) }\end{array}$ \\
\hline \multirow{4}{*}{ 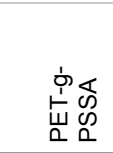 } & 0.2 & $3566 \pm 23$ & $60.7 \pm 1.2$ \\
\hline & 0.5 & $2115 \pm 34$ & $41.5 \pm 1.1$ \\
\hline & 0.7 & $1037 \pm 40$ & $8.6 \pm 1.3$ \\
\hline & 1 & $677 \pm 30$ & $7.2 \pm 1.2$ \\
\hline $\begin{array}{l}\text { Nafion } \\
\text { NR212 }\end{array}$ & --- & $368 \pm 26$ & $29 \pm 1.1$ \\
\hline
\end{tabular}

Table 1: The mechanical parameters for Nafion and PET-g-PSSA with degree of grafting $166 \%$ prepared from different concentration of chlorosulfonic acid.

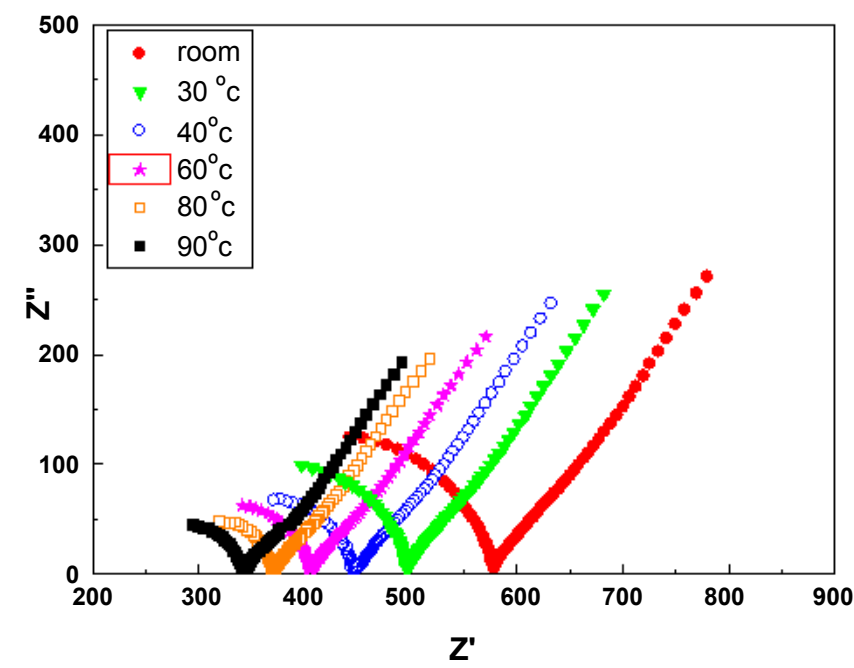

Figure 10: A C impedance spectra for PET-g-PSSA (D.G=166\%) at different temperatures.

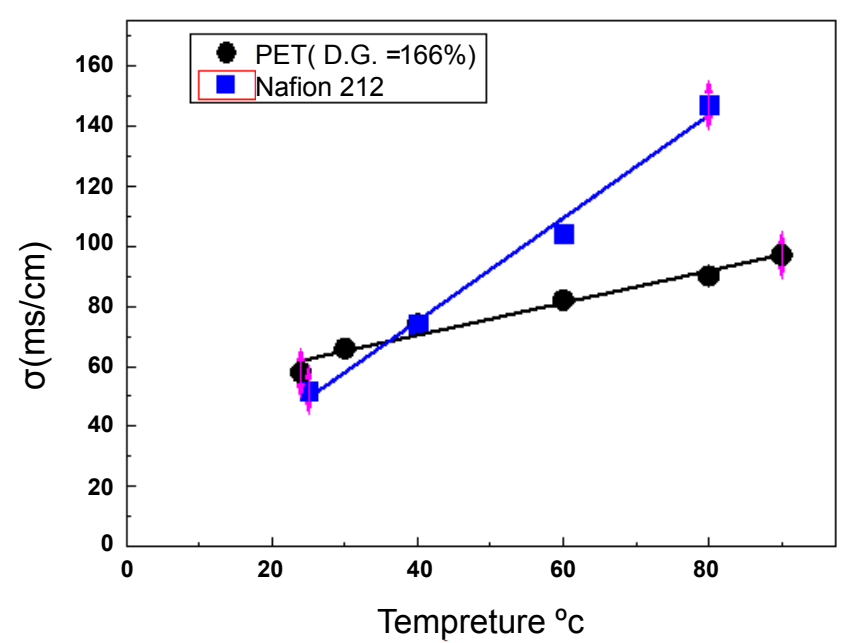

Figure 11: The proton conductivity $(\sigma)$ for PET-g-PSSA with degree of grafting $166 \%$ and Nafion 212 membranes at different temperatures. 
Citation: Abdel-Hady EE, Abdel-Hamed MO, Gomaa MM (2013) Preparation and Characterization of Commercial Polyethyleneterephthalate Membrane for Fuel Cell Applications. J Membra Sci Technol 3: 122. doi:10.4172/2155-9589.1000122

\begin{tabular}{|c|c|c|c|}
\hline Materials & D.G \% & Water uptake \% & Conductivity $\mathrm{mS} / \mathrm{cm}$ \\
\hline \multirow{5}{*}{ 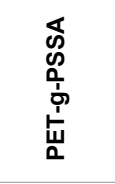 } & 8 & 8 & 8 \\
\hline & 18 & 13 & 16.5 \\
\hline & 83 & 32 & 18 \\
\hline & 113 & 50 & 46 \\
\hline & 166 & 59 & 58 \\
\hline Nafion & -- & 53 & 52 \\
\hline
\end{tabular}

Table 2: The conductivity and water uptake of PET g-PSSA as a function of D.G at room temperature.

increasing the proton mobility through the membranes. Due to the gradual increase in the proton conductivity for PET-g-PSSA with increase in temperature up to $90^{\circ} \mathrm{C}$ represents that the membrane can work efficiently up to $90^{\circ} \mathrm{C}$.

\section{Activation Energy $\left(\mathrm{E}_{\mathrm{a}}\right)$}

The activation energy (Ea), the minimum energy required for proton transport across the membrane, was calculated using the Arrhenius equation:

$$
\boldsymbol{\sigma}=\mathbf{A} \times \mathbf{e}^{-\mathrm{E} a / \mathrm{RT}}
$$

where $\sigma$ is the proton conductivity $\left(\mathrm{mScm}^{-1}\right), \mathrm{A}$ is a constant proportional to the number of charge carriers, Ea is the activation energy $\left(\mathrm{kJmol}^{-1}\right), \mathrm{R}$ is the universal gas constant $\left(8.314 \mathrm{Jmol}^{-1} \mathrm{~K}^{-1}\right)$, and $\mathrm{T}$ is the absolute temperature (K). The Arrhenius plot for PET-g-PSSA with degree of grafting $166 \%$ and Nafion membranes are shown in Figure 12. The plot of $\ln (\sigma)$ versus the inverse of temperature $(1000 / \mathrm{T})$ give a linear function with a slope $(-\mathrm{Ea} / \mathrm{R})$. From the plot, the activation energy Ea was calculated for the different membranes and found to be $6.3 \mathrm{kJmol}^{-1}$ and $16.3 \mathrm{kJmol}^{-1}$ for PET-g-PSSA, with degree of grafting $166 \%$ and Nafion, respectively.

The proton conduction mechanism in these membranes is known to occur by two routes. The first route is a hopping or jumping mechanism, also known as the Grotthuss model, in which a proton is passed through a channel of water molecules; the protons are transferred from one vehicle to the other by hydrogen bonds. The second route is a vehicle mechanism, where in a proton combines with solvent molecules, producing a complex which diffuses through the membrane. It was reported that for the hopping mechanism, the activation energy for proton conductivity should be around $14-40 \mathrm{~kJ} \mathrm{~mol}^{-1}[33,34]$. So, in Nafion the hopping mechanism is the predominant, while in PET-gPSSA, the vehicle mechanism is believed to exist.

\section{Methanol permeability}

DMFCs are attractive, especially for portable power applications. Membranes for use in DMFC system must both possess adequate proton conductivity and be an effective barrier for methanol crossover from the anode to the cathode compartment, to prevent loss of methanol and oxidation with oxygen, leading to a mixed potential [31]. One of the Nafion's drawbacks is its high methanol crossover in the DMFC application. This limitation is associated with the microstructure of Nafion. For determination of methanol permeability, the amount of methanol transported through the PET-g-PSSA with D.G $=166 \%$ and Nafion membranes was estimated repeatedly by spectrometer after drawing calibration curve between the methanol concentration and refractive index. The methanol permeability for PET-g-PSSA with D.G $=166 \%$ was found to be $1.2 \times 10^{-8} \mathrm{~cm}^{2} / \mathrm{s}$, which is lower than that of Nafion $\left(1.65 \times 10^{-6} \mathrm{~cm}^{2} / \mathrm{s}\right)$. This mean that the PET-g-PSSA with D.G $=166 \%$ is more reliable for fuel cell applications.

\section{DMFC performance of PET-g-PSSA membrane}

The single cell DMFC was performed at room temperature and $1 \mathrm{M}$ methanol solution for 120 hours. As can be seen from Figure 13, the performance curve has two trends; during the first $2 \mathrm{hrs}$, the output voltage of the single cell increases from 0.45 to 0.57 volt. Such an observation may be attributed to the activation of electrocatalyst and decrease in the internal resistance of the single cell [35]. In the following stage, the voltage of the single cell decreases to $0.51 \mathrm{~V}$. The results showed that the cell voltage is stable at $0.51 \mathrm{~V}$, which is better than obtained by Hasani-Sodrabadi et al. [36]. By considering the steady performance curve of the DMFC single cell, it is expectable that the durability and stability of the PET-g-PSSA membranes to be suitable for methanol fuel cell.

\section{Conclusions}

Polymer electrolyte membranes (PEMs) for fuel cells, also termed as proton exchange membranes, have been successfully prepared by UV-radiation grafting of styrene onto PET films, and consequent, selective sulfonation by chlorosulfonic acid. The PEMs displayed excellent thermal, mechanical and electrical properties. The maximum

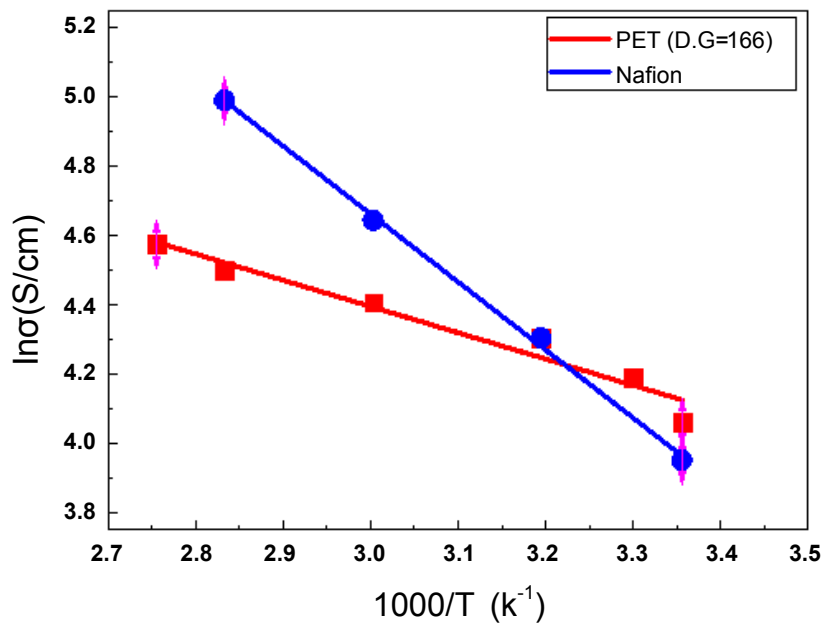

Figure 12: Arrhenius plots of proton conductivity $\sigma$ for PET-g-PSSA with degree of grafting $166 \%$ and Nafion 212 membranes.

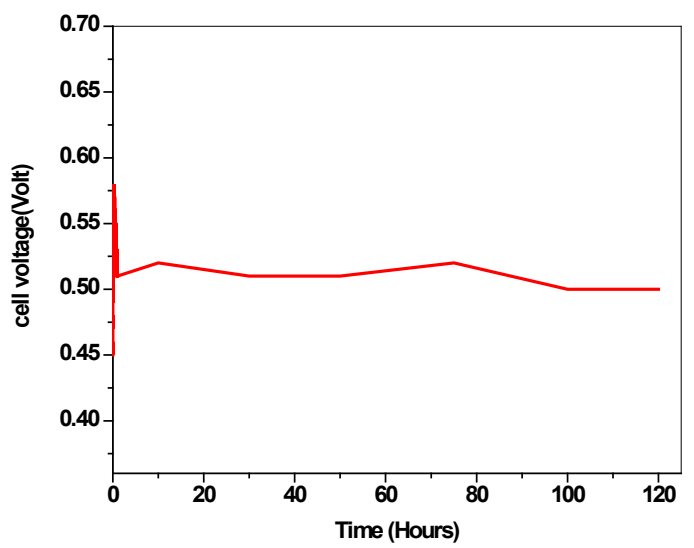

Figure 13: The cell voltage as a function of time. 
Citation: Abdel-Hady EE, Abdel-Hamed MO, Gomaa MM (2013) Preparation and Characterization of Commercial Polyethyleneterephthalate Membrane for Fuel Cell Applications. J Membra Sci Technol 3: 122. doi:10.4172/2155-9589.1000122

ion-exchange capacity (IEC) and the proton conductivity of the PEM were measured to be $0.7 \mathrm{mmol} \mathrm{g}^{-1}$ and $58 \mathrm{~m} \mathrm{Scm}^{-1}$, respectively. The activation energy was calculated as $6 \mathrm{k} \mathrm{jmol}^{-1}$ by Arrhenius plot, which reveals that the vehicle mechanism is the predominant conduction mechanism in PET-g-PSSA membranes. Due to their low coast, higher conductivity, suitable water uptake and low methanol permeability, PET-g-PSSA membranes are considered for use in DMFCs as alternatives to Nafion.

\section{Acknowledgements}

The authors wish to sincerely thank the STDF of Egypt, (ID220), for financially supporting this project.

\section{References}

1. Sopian K, Shamsuddin AH, Nejat VT (1995) Solar hydrogen energy option for Malaysia. Proceedings of the International Conference on Advances in Strategic Technology.

2. Zhou W, Xiao J, Chen Y, Zeng R, Xiao S, et al. (2010) Synthesis and characterization of sulfonated poly (ether sulfone ether ketone ketone) for proton exchange membranes. J Appl Polym Sci 117: 1436

3. Mauritz KA, Moore RB (2004) State of Understanding of Nafion. Chem Rev 104: $4535-4586$

4. Nasef MM, Hegazy EA (2004) Preparation and applications of ion exchange membranes by radiation-induced graft copolymerization of polar monomers onto non-polar films. Prog Polym Sci 29: 499-561.

5. Gubler L, Gursel SA, Scherer GG (2005) Proton exchange membranes prepared by radiation grafting of styrene/divinylbenzene onto poly(ethylene-alttetrafluoroethylene) for low temperature fuel cells. Fuel Cells 5: 317.

6. Dworjanyn PA, Garnett JL (1988) Synergistic effects of urea with polyfunctional acrylates for enhancing the photografting of styrene to polypropylene. J Polym Chem Polym Lett Ed 26: 135-138.

7. Hollahan JR (1974) Plasma Chemistry Industrial Application. Wiley, New York USA.

8. Wilkie CA, Deacon C (1996) Graft copolymerization of acrylic acid on to acrylonitrile-butadiene-styrene terpolymer and thermal analysis of the copolymers. Eur Polym J 32: 451-455

9. Hasegawa S, Suzuki Y, Maekawa Y (2008) Preparation of poly (ether ether ketone)-based polymer electrolytes for fuel cell membranes using grafting technique. Radiat Phys Chem 77: 617-621.

10. Asano M, Chen J, Maekawa Y, Sakamura T, Kubota H, et al. (2007) Novel UVinduced photografting process for preparing poly(tetrafluoroethylene)-based proton-conducting membranes. J Polym Sci A PolymChem 45: 2624-2637 .

11. Ismail AF, Zubir N, Nasef MM, Dahlan KM, Hassan AR (2005) Physicochemical study of sulfonated polystyrene pore-filled electrolyte membranes by electrons induced grafting. J Membr Sci 254: 189-196.

12. Li J, Kohei S, Shogo I, Saneto A, Shigetoshi I, et al. (2005) Pre-irradiation induced grafting of styrene into crosslinked and non-cross linked poly tetrafluoroethylene films for polymer electrolyte fuel cell applications II Characterization of the styrene grafted films. Eur Polym J 41: 547-555.

13. Nasef MM, Saidi H, Dessouki AM, El-Nesr EM (2000) Radiation-induced grafting of styrene onto poly(tetrafluoroethylene), PTFE films I Effect of grafting conditions and properties of the grafted films. Polym Int 49: 399-406.

14. Holmberg, Lehtinen T, Näsman J, Ostrovskii D, Paronen M, et al. (1996) Structure and properties of sulfonated poly [(vinylidene fluoride)-g-styrene] norous membranes porous membranes. J Mater Chem 6: 1309-1317.

15. Flint SD, Slade RCT (1997) Investigation of radiation-grafted PVDF-g polystyrene-sulfonic-acid ion exchange membranes for use in hydrogen oxygen fuel cells. Solid State lonics 97: 299-307.

16. Elomaa M, Hietala S, Paronen M, Walsby N, Jokela K, et al. (2000) The state of water and the nature of ion clustersincrosslinked proton conducting membranes of styrene grafted and sulfonatedpoly(vinylidene fluoride). J Mater Chem 10: 2678-2684.
17. Kyoung RP, Phil HK, Young CN (2005) Preparation of PFA-g-polystyrene sulfonic acid membranes by the Gamma-radiation grafting of styrene onto PFA film. React Funct Polym 65: 47-56.

18. Brack HP, Bührer HG, Bonorand L, Scherer GG (2000) Grafting of preirradiated poly(ethylene-alt-tetrafluoroethylene) films with styrene influence of base polymer film properties and processing parameter. J Mater Chem 10: 1795-1803.

19. Scott K, Taama WM, Argyropoulos $P$ (2000) Performance of the direct methano fuel cell with radiation-grafted polymer membranes. J Membr Sci 171: 119-130.

20. Mostak Ahmed, Mubarak A Khan, Md Pezwan Miah, Syed Abdul Monim, M Anwar H Khan (2011) Gamma Radiation-induced graft copolymerization of styrene onto polyethyleneterephthalate fims application in fuel cell technology as a proton exchange membrane. J Macromol Sci A Pure Appl Chem 48: $927-$ 936.

21. Nasef MM (2000) Gamma radiation-induced graft copolymerization of styrene onto poly(ethyleneterephthalate) films. J Appl Polym Sci 77: 1003-1012.

22. Kattan M, El-Nesr E (2006) Gamma-Radiation-induced graft copolymerization of acrylic acid onto poly (ethylene terephthalate) films A study by thermal analysis. J Appl Polym Sci 102: 198-203.

23. Nasef MM, Saidi H, Dessouki AM, El-Nesr EM (2000) Radiation-induced Grafting of Styrene onto Poly(tetrafluoroethylene) (PTFE) Films I Effect of Grafting Conditions and Properties of the Grafted Films. J Polym Int 49: 399406

24. Nasef MM, Saidi H, Nor HM (2000) Proton exchange membranes prepared by simultaneous radiation grafting of styrene onto poly(tetrafluoroethylene-cohexafluoropropylene) films i effect of grafting conditions. J Appl Polym Sci 76: 220-227.

25. Rager T (2003) Pre-Irradiation grafting of styrene/divinylbenzene onto poly (tetrafluoroethylene-co-hexafluoropropylene) from non-solvents. Helv Chim Acta 86: 1.

26. Walsby N, Paronen M, Juhanoja, Sundholm (2001) Sulfonation of styrenegrafted poly(vinylidene fluoride) films. J Appl Polym Sci 81: 1572-1580.

27. Zhou W, Xiao J, Chen Y, Zeng R, Xiao S, et al. (2010) Synthesis and characterization of sulfonated poly(ether sulfone ether ketone ketone) for proton exchange membranes. J Appl Polym Sci 117: 1436-1445.

28. Takahashi, Okonogi H, Hagiwara T, Maekawa Y (2008) Preparation of polymer electrolyte membranes consisting of alkyl sulfonic acid for a fuel cell using radiation grafting and subsequent substitution/elimination reactions. J Membr Sci 324: 173-180.

29. Nasef M, Zubir NA, Ismail AF, Dahlan KZM, Saidi H, et al. (2006) Preparation of radio chemically pore-filled polymer electrolyte membranes for direct methanol fuel cells. J Power Sources 156: 200-210.

30. Shoibal Banerjee, Dennis E (2004) Nafion ${ }^{\circledR}$ perfluorinated membranes in fuel cells. Curtin Journal of Fluorine Chemistry 125: 1211-1216.

31. Tauqir A Sherazi, Shujaat Ahmad, Akram Kashmiria M, Michael Guiver (2008) Radiation-induced grafting of styrene onto ultra-high molecular weight polyethylene powder and subsequent film fabrication for application as polymer electrolyte membranes Influence of grafting conditions. J Membr Sci 325: 964972.

32. Abdel-Hady EE, El-Toony MM, Abdel-Hamed MO, Hammam AM (2011) Grafting of styrene onto commercial PTFE membrane and sulfonation for possible use in fuel cell. J Membr Sci Technol 1: 3.

33. Li L, Zhang J, Wang Y (2003) Sulfonatedpoly ether ether ketone membranes for direct methanol fuel cell. J Membr Sci 226: 159-167.

34. Nagarale RK, Gohil GS, Shahi VK (2006) Sulfonated polyether ether ketone / polyaniline composite proton-exchange membrane. J Membr Sci 280: 389-396.

35. Zhai $\mathrm{Y}$, Zhang $\mathrm{H}$, Zhang $\mathrm{Y}$, Xing $\mathrm{D}$ (2007) A novel $\mathrm{H}_{3} \mathrm{PO}_{4} /$ Nafion-PBI composite membrane for enhanced durability of high temperature PEM fuel cells. J Power Sources 169: 259

36. Hasani-Sadrabadi MM, Dashtimoghadam E, Sarikhani K, Fatemeh S, et al. (2010) Electrochemical investigation of sulfonated poly(ether ether Ketone)/clay nano composite membranes for moderate temperature fuel cell applications. J Power Sources 195: 2450-2456. 